\title{
THE SEISMIC BEHAVIOUR OF STONE MASONRY GREEK ORTHODOX CHURCHES
}

\author{
George C. Manos \\ Laboratory of Strength of Materials and Structures, Dept. Civil Engineering, \\ Aristotle University, Thessaloniki, Greece \\ e-mail: gcmanos@civil.auth.gr
}

\begin{abstract}
The seismic behaviour of structural systems representing Greek Orthodox churches is examined. All these churches are made of stone masonry in various architectural forms. During the years such churches developed damage to their stone masonry structural elements due to the amplitude of the gravitational forces acting together with the seismic forces. In certain cases such damage was amplified due to the deformability of the foundation. The behaviour of structural systems representing Greek Orthodox churches was simulated through linear and non-linear numerical models. The numerical results together with assumed strength values or failure criteria were utilized to predict the behaviour of the various masonry parts in in-plane shear and flexure as well as out-of-plane flexure. The deformability of the foundation partly explains the appearance of structural damage as can be seen both from observations and the numerical predictions. A limit-state methodology is presented whereby the demands obtained from linear elastic numerical models combined with limit-state inplane behaviour of unreinforced stone masonry walls in shear/flexure or diagonal tension can yield reasonably good predictions of observed behaviour. Furthermore, the possibilities offered by non-linear inelastic numerical analyses as alternative means for examining the performance of unreinforced stone masonry walls is also briefly presented. Towards this objective, non-linear inelastic numerical simulation results are presented that yield reasonably good agreement with the relevant measured behaviour of stone masonry wall specimens of prototype dimensions that were subjected to simultaneous vertical compression and horizontal cyclic seismictype loading in the laboratory. The obtained results from these specimens were utilized to also validate an expert system based on this limit-state methodology. Again, the observed behaviour was predicted with reasonable accuracy in terms of bearing capacity and mode of failure by this expert system.
\end{abstract}

\section{Keywords}

Greek Orthodox Churches, Stone masonry, In-plane behaviour, Gravitational forces, Seismic actions, Foundation deformability, Limit-state, Non-linear behaviour

\section{Introduction}

Various parts of Greece have been subjected during the years to a number of damaging earthquakes (GEER, 2014; Papazachos et al., 2003; Manos, 2011). One of the most demanding tasks for counteracting the consequences of relatively intense seismic events is the effort to ensure the structural integrity of "old" churches that usually sustain considerable damage. There are two distinct structural systems that these "old" churches usually belong to. The "Basilica" architectural form is shown in figures $1 \mathrm{a}$ and $1 \mathrm{~b}$ whereas the so called "crucifix form with a central dome" architectural form is shown in figures $2 \mathrm{a}$ and $2 \mathrm{~b}$.

The seismic performance of a considerable number of such "old" Christian church structural systems has been studied by Manos et al. (2008, 2009, 2010(1,2), 2011, 2013(1,2), 2012, 2014, $2015(1,2,3)$ ) utilizing a variety of numerical simulations as presented in section 2 . In some cases, the foundation was considered to be nondeformable; however, this is a gross approximation as in most cases these churches are founded on deformable soil. In some instances it is evident that the soil-foundation deformability amplified the structural damage (Manos et al. 2013(1), 2014, $2015(2,3))$. Consequently, the numerical simulation tries to include in a simple way the effect of the soilfoundation deformability, as presented in section 3 . The main objective of all these numerical simulations is to obtain realistic estimates of the demands $\left(\mathbf{S}_{d}\right)$ that a particular load combination poses on various 


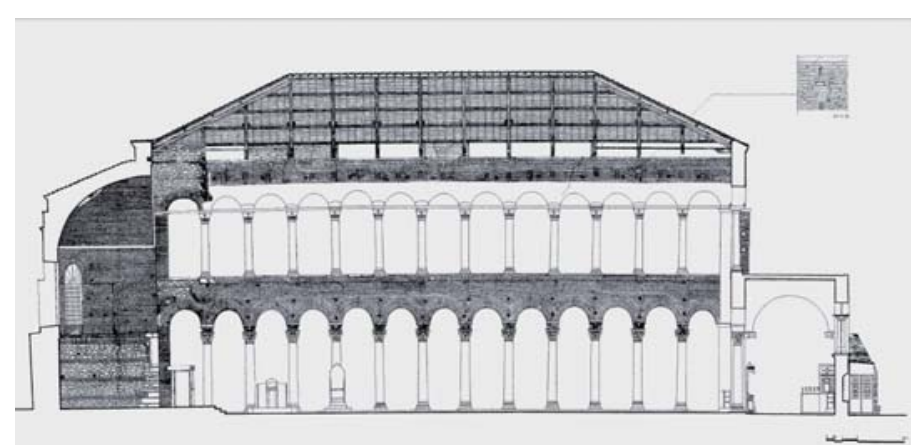

a) Longitudinal East-West section, View from North

Fig. 1. The Basilica church of Achiropoiitos, Thessaloniki, Greece

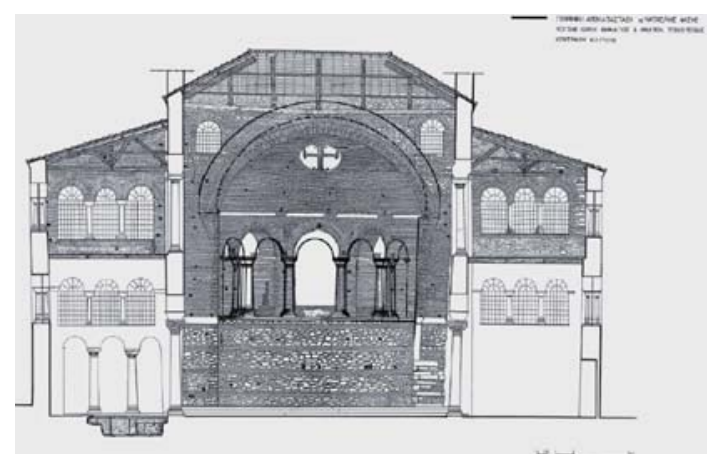

b) Transverse North-South section, View from East
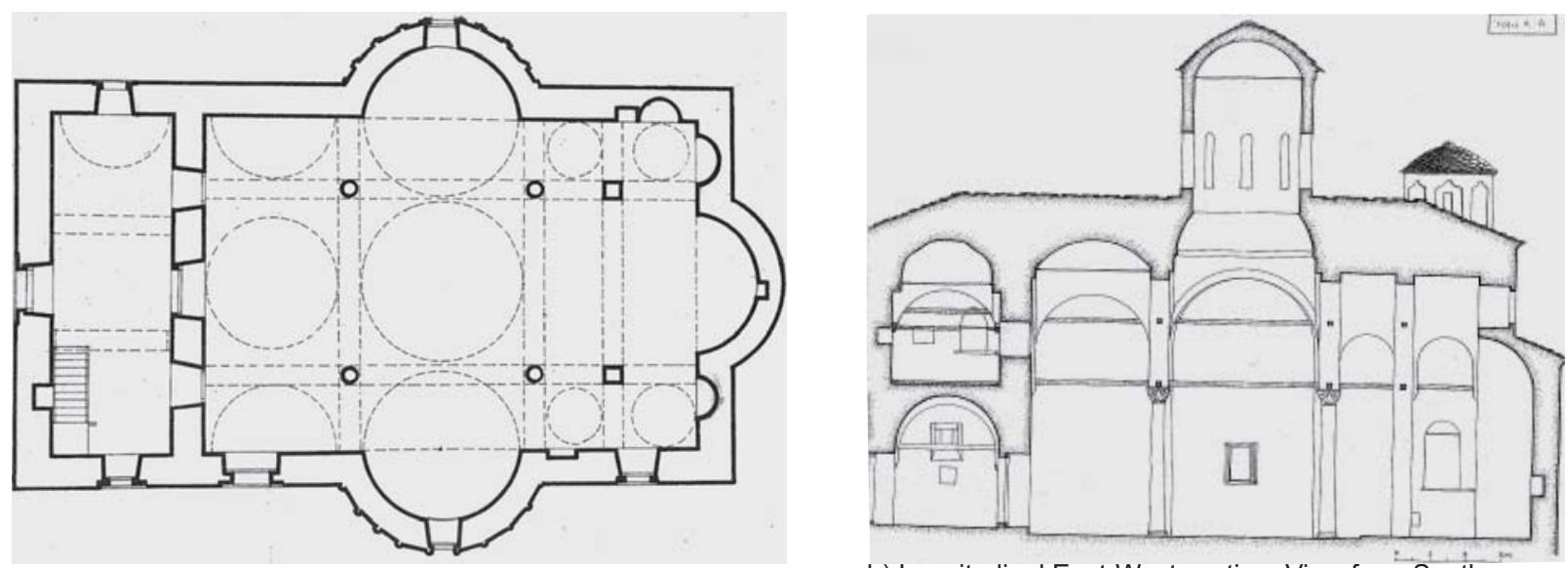

b) Longitudinal East-West section, View from South

a) Plign 2. The church of Holy Trinity (Agia Triada) at Vithos - Voio - Kozani - Greece

types of stone masonry elements. This is needed in order to be able to monitor the ability of the various stone masonry structural elements to exhibit (or not) satisfactory performance, that is to satisfy (or not) a limit state condition representing either an inplane shear / flexural mode of failure or an out-ofplane flexural mode of failure. Towards this objective it is necessary to obtain estimates of the relevant in-plane shear / flexural or out-of-plane flexural capacities $\left(\mathbf{R}_{\mathrm{d}}\right)$. This is briefly outlined in section 4 . The most vulnerable masonry parts of these "old" churches are the masonry piers between door and window openings of the vertical peripheral walls. Such structural elements are presented in section 5 together with a particular experimental and numerical study that tries to predict the non-linear behaviour of such stone masonry piers. For this purpose, stone masonry piers of prototype dimensions built with prototype materials, which resemble the ones used in "old" churches, are subjected to a combination of vertical loads and horizontal seismic-type actions in the laboratory. The measured behaviour is then utilised to validate the employed numerical simulation by comparing the predicted with the observed behaviour.

\section{Numerical simulation of the seismic} performance

2.1. Forming the numerical model: A relatively simple way to numerically simulate the seismic performance of structural systems representing "old" churches is to employ shell finite elements for the stone masonry parts; in this way both in-plane as well as out-of-plane deformations and states of stress develop from transferring the imposed loads. This numerical simulation through shell finite elements follows the mid-plane of the actual stone masonry parts. Frame elements are also employed to numerically simulate the wooden trusses as well as the slender columns of the interior. In order to realistically approximate the stiffness of the masonry parts an appropriate value for the Young's Modulus is assumed, in the range of $1500 \mathrm{MPa}$ or less. This is based on experimental measurements of the deformability of such stone masonry elements when they are subjected to a combination of vertical loads and horizontal seismic-type actions rather than pure axial compression tests.

2.2. Load Combinations: As already stated, the main objective of these numerical simulations is to obtain realistic estimates of the demands $\left(\mathbf{S}_{d}\right)$ that 
a particular load combination imposes on various stone masonry parts that form the total structural system. In all these studies the employed load combination is one that includes the gravitational loads (G) together with the earthquake forces Ex and/or Ey along the longitudinal and transverse directions, respectively. The load combinations $0.9 \mathrm{G} \pm 1.4 \mathrm{Ex}$ or $0.9 \mathrm{G} \pm 1.4 \mathrm{Ey}$ can be used instead of the load combinations $\mathrm{G} \pm \mathrm{Ex} \pm 0.3 \mathrm{Ey}$ or $\mathrm{G} \pm 0.3 \mathrm{Ex} \pm \mathrm{Ey}$, specified by the seismic codes (Eurocode 8; Manos, 1994; Provisions of Greek Seismic Code 2000; Provisions of Greek Seismic Code, 2003); this is an indirect but simple way to combine the two horizontal components of the seismic action, bearing in mind that the stone masonry walls are checked separately for the in-plane and out-of-plane state of stress (Gulkan at al., 1990). Furthermore, from extensive studies it was demonstrated that the load combinations $0.9 \mathrm{G} \pm 1.4 \mathrm{Ex}$ or $0.9 \mathrm{G} \pm 1.4 \mathrm{Ey}$ lead to more conservative (relatively larger) demands than the load combinations $\mathrm{G} \pm \mathrm{Ex} \pm 0.3 \mathrm{Ey}$ or $\mathrm{G} \pm 0.3 \mathrm{Ex} \pm \mathrm{Ey}$. In addition, because gravity forces usually lead to compressive state of stress normal to the bed-joints in critical regions of vertical stone masonry walls and thus increase their corresponding shear strength, a reduction of the gravity forces is introduced ( $0.9 \mathbf{G}$ ) in order to lead to conservative (relatively smaller) shear strength estimates.

2.3. Linear-elastic numerical analyses: The numerical model simulating the structural system of the "old" stone masonry churches is subjected first to the gravitational forces and then to the earthquake actions. The latter can be applied in various different ways depending on the choice of method of analyses. Initially, a linear-elastic behaviour is assumed for the various stone masonry parts and their connections. A direct consequence is that the results from the earthquake actions can be super-imposed on the results from the gravitational forces. Despite the fact that this assumption is a simplification of the behaviour of stone masonry structures under seismic loading, it has the great advantage of simplicity that leads to numerical solutions for seismic type loads within realistic limits of computer memory and time. Moreover, it also has the advantage of producing various deformation patterns and corresponding state-of-stress for all structural elements that can be easily understood when linked with the expected transfer of loads even if they are a product of this basic simplification of linear-elastic behaviour. One popular method of analysis for earthquake actions is the dynamic spectral method whereby the amplitude of the seismic forces is based on accepted design or site-defined spectral curves. A first check of the numerical analyses results involves a thorough study of the resulting dynamic eigen-modes of vibration with their corresponding eigen-frequencies and participation mass-ratios (Manos et al., 2008,
2009, 2010(1,2), 2011, 2013(1,2), 2012, 2014, $2015(1,2,3))$. Through a screening process of these dynamic characteristics one has the ability to exercise his structural engineering experience by removing eigen-modes that are the product of this linear-elastic behaviour combined with the rigid connections of the various stone masonry elements assumption, thus not including in the dynamic analysis modes of dynamic response that are obviously unrealistic for stone-masonry structures but still retaining the significance of the translational modes for the structure as a whole or the fundamental in-plane and out-of-plane modes of vibration of the main stone masonry parts. Should the remaining eigen-modes not mobilize a significant part of the total structural mass (e.g. larger than $90 \%$ ) an appropriate amplification factor is introduced to compensate for this. In defining the earthquake actions through a spectral curve for the longitudinal Ex and the transverse Ey directions it is necessary to also define a value for the behaviour factor ( $\boldsymbol{q}$, (Eurocode 8)) the value for the importance factor $\left(y_{l}\right.$ (Eurocode 8$)$ ) and the soil conditions for the structure at hand. For unreinforced masonry a value in the range of 1.5 to 2.0 is commonly employed for the behaviour factor ( $\boldsymbol{q}$, (Eurocode 8; Provisions of Greek Seismic Code 2000; Provisions of Greek Seismic Code, 2003)). The value for importance factor can be derived from the fact that for common occupancy contemporary residential buildings the value of this factor is 1.0 , based on $10 \%$ probability of exceeding the design ground acceleration in a period of 50 years (Eurocode 8; Manos et al., 1994; Provisions of Greek Seismic Code 2000; Provisions of Greek Seismic Code, 2003). Prototype earthquake acceleration ground motions and their corresponding response spectral curves can be employed alternatively, provided that this choice is based on sufficient justification for a particular "old" stone masonry church. In this case, a constant ductility response spectral curve can also be employed with a ductility value in the range of the values mentioned before for the behaviour factor (q (Eurocode 8; Manos et al., 1994; Provisions of Greek Seismic Code 2000; Provisions of Greek Seismic Code, 2003)).

The dynamic spectral method of analysis has the advantage of producing results that are based on the dynamic nature of the earthquake actions. However, because these results are produced from a statistical combination of the contributions of the eigen-modes, the deformation patterns and the maximum values of the stresses in the critical locations cannot be easily selected and studied. An alternative method of analysis is an "equivalent linear pushover" method whereby all the structural masses are subjected to a constant value of horizontal acceleration. The amplitude of this acceleration is defined so that the 
resulting base shear value in either the longitudinal Ex or the transverse Ey direction is equal to the corresponding base shear value that resulted from the spectral dynamic analysis. Finally, the earthquake actions can be alternatively applied through a dynamic time history analysis. In this case, a horizontal ground acceleration time history can be introduced in either the longitudinal Ex or/and in the transverse Ey direction. Moreover, this can be done employing the recordings of a prototype earthquake event provided that this choice is based on sufficient justification for a particular "old" stone masonry church. The results that are obtained through such an analysis are usually of a very large volume that need particular experience and efficient postanalysis tools in order to extract the most significant information. The previously described linear-elastic methods of analyses in order to determine the demands $\left(\mathbf{S}_{d}\right)$ at various stone masonry structural elements can be combined next with the definition of the corresponding capacities keeping in mind certain realistic limit-state scenarios, as will be detailed in section 4 .

2.4. Non-linear numerical analyses: The same finite element representation that was used for the linear elastic analyses of the stone-masonry churches can also be employed for the non-linear numerical analyses. However, this depends upon the nonlinear analyses options that are incorporated in the software to be utilized (Ramalho et al., 2008). Thus, Manos et al. (2008) employed shell finite elements as described in 2.1. Then the LUSAS software package was used to perform non-linear analyses of the church of Agia Triada for seismic type loading, employing three alternative modified Von-Misses failure envelopes in a non-linear, step-by-step incremental analysis (see also section 5). Betti and Vignoli (Betti \& Vignoli, 2008) employed brick-type finite elements together with the software package ANSYS to investigate the seismic performance of the Farneta Abbey, a Basilica-type structure, employing a Drucker-Prager perfectly plastic criterion. The most important step in this type of non-linear analyses is to select a non-linear material model that can simulate in a realistic manner the non-linear behaviour of the stone-masonry structural elements under combined gravitational and seismic type loading. Due to the large computational requirements these non-linear analyses are of a static "push-over" nature whereby the structure is subjected initially to the gravitational forces and then to a realistic predetermined form of deformation pattern that gradually increases in a step-wise manner (Manos, 2008). This type of nonlinear analyses can be further refined by assuming a number of pre-determined failure modes and then selecting as most probable failure mode the one that requires the lowest level of force for its development.

\section{Soil-Foundation Deformability}

The foundation of "old" masonry churches is considered to be formed by a peripheral masonry strip that is an extension of the masonry walls in the sub-soil at a certain depth. In order to study numerically the soil-foundation deformability the following process is utilized (Manos et al., 2013(1), $2014,2015(2,3)$ ). First, a numerical model of the structure and the masonry foundation strip is formed, modelled with shell elements whereas the soil volume underneath is modelled with solid "brick" finite elements with linear elastic properties thus representing the volume of soil under the church extending to a certain depth below the foundation soil interface. When reliable geotechnical data are not readily available the investigation of the soilfoundation deformability is attempted in a parametric way. Initially, a shear wave velocity value equal to $420 \mathrm{~m} / \mathrm{sec}$ is assumed for example and that value together with a soil density equal to $20 \mathrm{KN} / \mathrm{m} 3$ leads to a shear modulus equal to $354 \mathrm{MPa}$ and a Young's modulus value for the soil equal to $1000 \mathrm{MPa}$, which represents a rather hard soil. Alternatively, a shear wave velocity value equal to $200 \mathrm{~m} / \mathrm{sec}$ leads to a Young's modulus value for the soil equal to $230 \mathrm{MPa}$, which represents a medium stiffness soil (Manos, 2015(2)). A numerical simulation that includes the superstructure, the foundation masonry strip and the soil layers, as shown in figure $3 a$, is then subjected to the dead weight $(\mathbf{G})$. The resulting vertical deformation patterns for the 1st $(\mathrm{Vs}=419 \mathrm{~m} / \mathrm{sec})$ and 2nd (Vs=200m/sec) case of soil deformability, are obtained all along the foundation-soil interface (figures $3 b$ and $3 c$ ).

Next, in order to simplify the final numerical model of the examined "old" stone masonry churches including the soil-foundation deformability, a simple alternative numerical model of the foundation masonry strip - soil interface is formed. This model retains all the aspects of the superstructure and the foundation masonry strip. However, this time the effect of the deformability of the soil layers is represented by two-node 3-D link elements with such an axial stiffness that when the same dead weight is applied as was done before, the resulting vertical deformation pattern at the bottom surface of the foundation - soil interface is as close as possible to the values obtained before with the full presence of the soil layers (figure $3 a, b, c)$. The following summarise the most significant effects of soil-foundation deformability on their seismic behaviour:

- A lengthening of the eigen-period values and a mobilization of larger modal mass ratios when the deformability of the soil-foundation is included than when the soil is presumed non-deformable. This in turn usually leads to an increase in the values of the demands $\left(\mathbf{S}_{\mathrm{d}}\right)$. 


\section{Architecture and Engineering Volume 1 Issue 1}

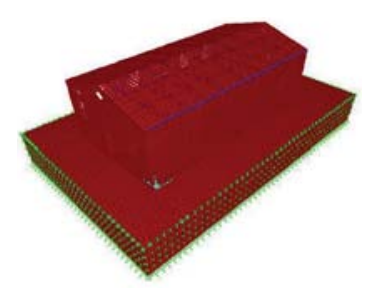

a)

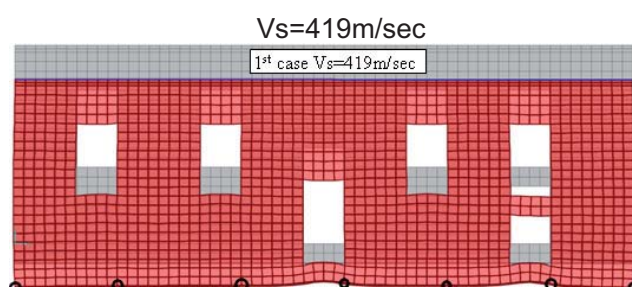

b) Vertical deflections the soil-foundation interface

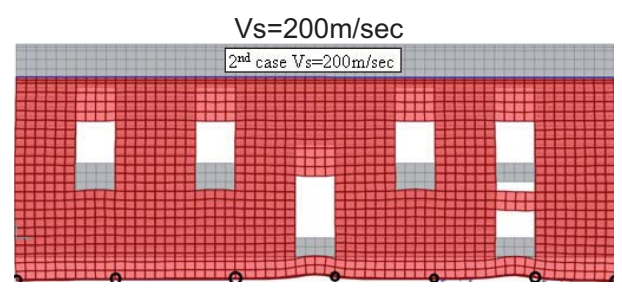

c) Vertical deflections the soil-foundation interface

Fig. 3. 3-D model of the superstructure, the soil-foundation interface and the soil layers

- This increase in the demands $\left(\mathbf{S}_{d}\right)$ becomes more pronounced when the structural system is nonsymmetric or the deformability of the foundation is non-uniform in plan. This in turn result in significant stress concentration for the structural elements, even only for the gravitational forces, that can lead to spectacular structural failure, as was the case of the church of "The Assumption of the Virgin Mary" at Dilofo-Kozani-Greece (figure 4, (Manos et al., 2014, 2015(1,3)).

\section{Expected seismic performance on the basis of the linear analyses demands}

The demands $\left(\mathbf{S}_{d}\right)$ for the various stone masonry structural elements, as obtained from the linearelastic numerical models are utilized in the following two ways: First, the results can be studied in terms of normal and shear stresses $\boldsymbol{\sigma}_{11} \boldsymbol{\sigma}_{22} \mathbf{T}_{12}$. These results are usually presented in terms of coloured diagrams; by studying them, areas of stress concentration can be identified that can be compared with damaged areas as a first qualitative check, as seen in figures 4 and 5 .

Next, certain commonly used masonry failure criteria can be adopted for either in-plane tension/ compression or shear/compression or out-of-plane tension. All the masonry parts are examined in terms of the obtained in-plane and out-of-plane stress demands $\left(\mathbf{S}_{\mathrm{d}}\right)$ against the corresponding normal and shear stress capacities $\left(\mathbf{R}_{\mathrm{d}}\right)$. In defining these

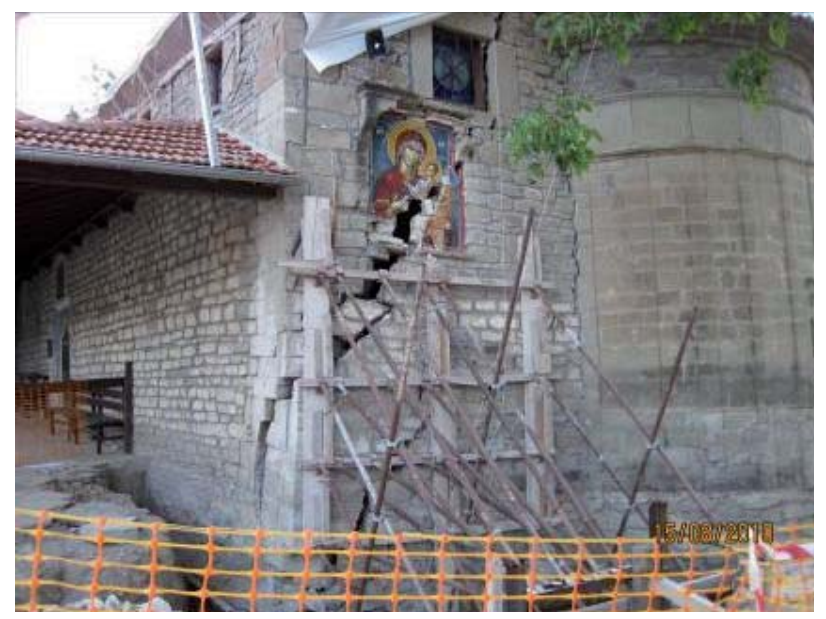

Damage to the South-East corner capacities, use can be made of existing guidelines for the design of contemporary masonry structures (e.g. Eurocode 6) or experimental data which can be substantiated as bearing some resemblance to the stone masonry structural elements at hand (Eurocode 6). Table 1 lists the assumed mechanical characteristics for the stone masonry of the church of Holy Trinity (Agia Triada) at Vithos - Voio - Kozani Greece (Manos et al., 2014, 2015 (1,3)). Moreover, a Mohr-Coulomb failure envelope was adopted for the in-plane shear limit state of the stone masonry, when a $\sigma_{n}$ normal stress is acting simultaneously with a shear stress demand. This is defined through the equation 1 (Eurocode 6).

$$
f_{v k}=f_{v k o}+0.4 \sigma_{n}
$$

where: $\mathbf{f}_{\mathrm{vko}}$ is the shear strength of the stone masonry when the normal stress $\sigma_{\mathrm{n}}$ is zero; $\mathbf{f}_{\mathrm{vko}}$ was assumed to be equal to $0.19 \mathrm{~N} / \mathrm{mm} 2$.

By comparing the capacities $\left(\mathbf{R}_{\mathrm{d}}\right)$ with the demands $\left(\mathbf{S}_{\mathbf{d}}\right)$ the following performance criterion is checked:

$$
\text { Ratio }=R_{\mathrm{i}}=\mathrm{R}_{\mathrm{d}} / \mathrm{S}_{\mathrm{d}}>1
$$

a satisfactory performance is signified. The opposite is true when Ratio $=\mathbf{R}_{\mathrm{i}}=\mathbf{R}_{\mathrm{d}} / \mathbf{S}_{\mathrm{d}}<\mathbf{1}$ whereby a non-satisfactory performance is signified. In order to further detail the use of the above performance criterion the following capacity over demand ratios are defined: $\mathbf{R}_{\sigma}$ is the ratio of the in-plane tensile

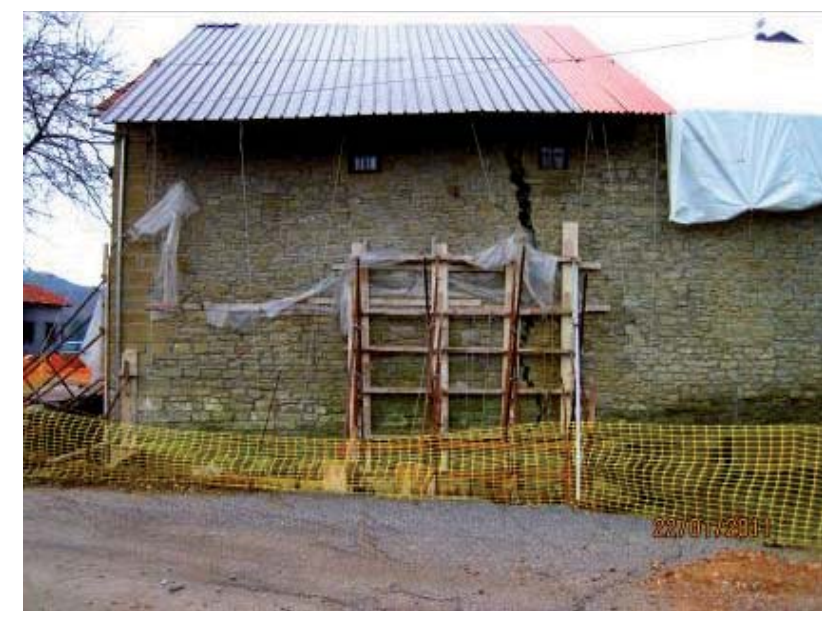

Damage to the North longitudinal wall

Fig. 4. The stone masonry church of "The Assumption of the Virgin Mary" at Dilofo-Kozani-Greece 


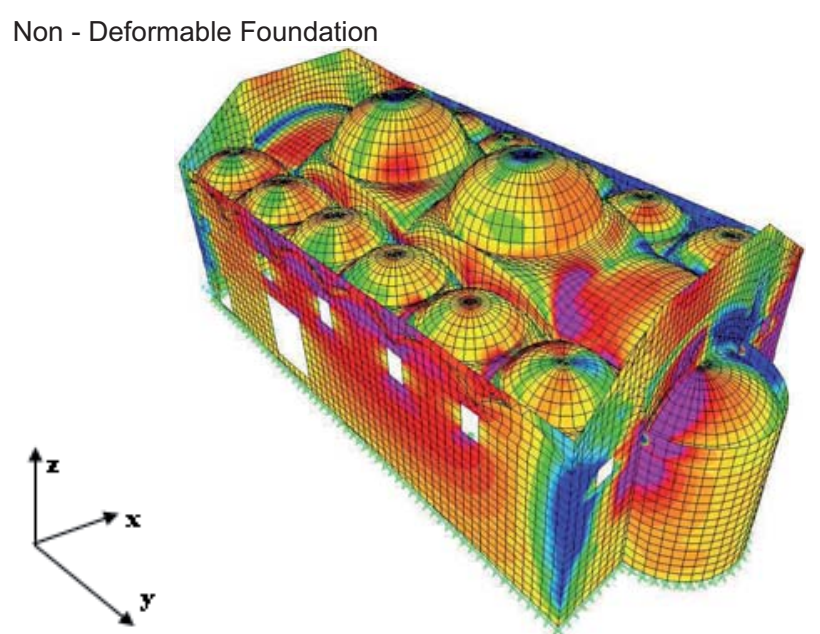

a) $\sigma_{11}$ bottom face, ${ }_{\max } \sigma=0.51 \mathrm{MPa}$

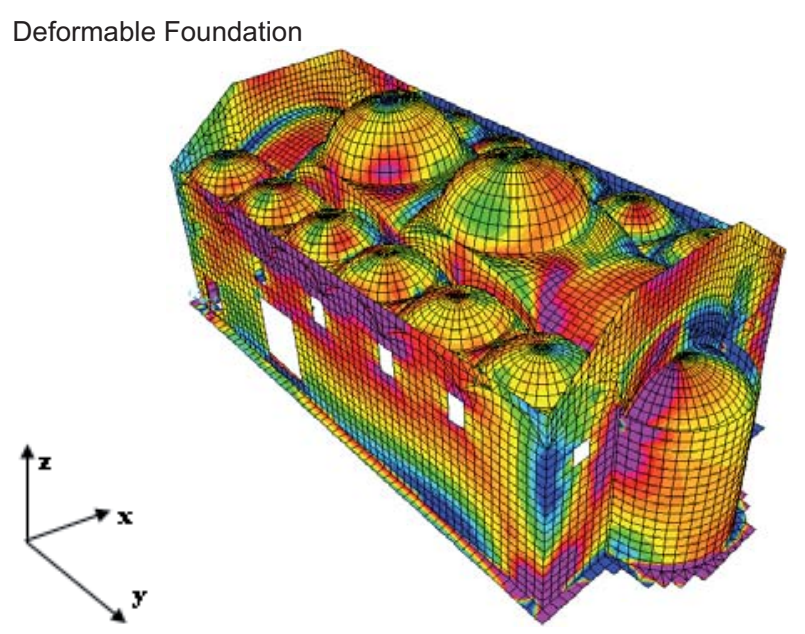

b) $\sigma_{11}$ bottom face ${ }_{\max } \sigma=0.64 \mathrm{MPa}$

Fig. 5. Load Combination 0.9G+1.4(+Ex). The stone masonry church of "The Assumption of the Virgin Mary" at Dilofo-Kozani-Greece

strength value $\left(\mathbf{f}_{\mathrm{xk} 1}\right.$ or $\left.\mathbf{f}_{\mathrm{xk} 2}\right)$ over the corresponding normal tensile stress demands $\boldsymbol{\sigma}_{22}$ or $\boldsymbol{\sigma}_{11}$, respectively. $\mathbf{R}_{\boldsymbol{T}}$ is the ratio of the in-plane shear strength value $\left(\mathbf{f}_{\mathrm{vk}}\right.$, equation 1) over the corresponding shear stress demand $\mathbf{T}_{12}$. Finally, $\mathbf{R}_{\mathbf{M}}$ is the ratio of the out-ofplane tensile strength value $\left(\mathbf{f}_{\mathrm{xk} 1}\right.$ or $\left.\mathbf{f}_{\mathrm{xk} 2}\right)$ over the corresponding tensile stress demand $\boldsymbol{\sigma}_{22}$ or $\boldsymbol{\sigma}_{11}$, respectively. As already stated, ratio values smaller than one $\left(\mathbf{R}_{\sigma}, \mathbf{R}_{T}, \mathbf{R}_{\mathbf{M}}<1\right)$ predict that the corresponding limit state condition was exceeded thus signifying prediction of structural damage. It was shown by numerous studies that the methodology described here correlates quite well with observed damage or with predictions of structural damage through the non-linear approach (section 5).

Taking this rationale one step further the following can also be stated as being valid. By obtaining in the same location of a structure (a section of a structural element) ratio values $\mathbf{R}_{\sigma,}, \mathbf{R}_{\mathrm{T}}, \mathbf{R}_{\mathrm{M}}$ with all or some of them being smaller than $1^{\prime}\left(\mathbf{R}_{\sigma}, \mathbf{R}_{\mathrm{T},} \mathbf{R}_{\mathbf{M}}<1\right)$ the damage scenario that can be predicted as prevailing is the one that corresponds to the limit-state with the smallest ratio value. Figures $6 \mathrm{a}$ and $6 \mathrm{~b}$ depict the $\mathbf{R}_{\mathbf{T}}$ ratio values of the in-plane shear strength / shear demand for the load combination 0.9G+1.4Ey for the internal transverse wall, which separates the main church from the women's quarters situated at the west portion of the church of Holy Trinity (Agia Triada) at Vithos - Voio - Kozani - Greece (Manos et al. 2014, 2015(1,3)). Shear damage is predicted by these numerical analysis results as can be seen from the $\mathbf{R}_{\mathbf{T}}$ ratio values that are well below one $\left(\mathbf{R}_{\mathbf{T}}<1\right)$ in many locations. Moreover, when comparing the ratio values between figures $6 a$ and $6 b$ for the same locations it can be seen that the deformability of the foundation leads this ratio to obtain even smaller values than for the case of the non-deformable foundation. This demonstrates the detrimental effect of the flexibility of the foundation for this church, as described in section 2. The structural element capacities can be found either directly from the strength values, when one performs an evaluation of the performance of a damaged structure or with the introduction of the appropriate safety factors for stone masonry $(\boldsymbol{r})$ when one performs an evaluation of the performance of a structure for design purposes (Eurocode 6). Initially, the $\mathbf{R}_{\sigma}, \mathbf{R}_{\mathrm{T}}, \mathbf{R}_{\mathrm{M}}$ ratio values are found for the maximum values of stress demands which are obtained through the numerical simulations. However, finding ratio values $\left(\mathbf{R}_{\mathbf{\sigma}}, \mathbf{R}_{\mathrm{T}}, \mathbf{R}_{\mathrm{M}}\right)$ smaller than 1 locally, through such maximum stress demand values, does not imply that the limit-state capacity of a structural element is exceeded. An alternative approach has been proposed by Manos et al (2015(1)) that is based on making this capacityover-demand checks in the level of a horizontal cross-section for vertical stone masonry structural elements. This can be extended for cross-sections of different orientations and for stone masonry structural elements other than vertical. However, as the most significant structural elements for the safe earthquake performance of stone masonry Greek Orthodox churches are the vertical stone masonry walls and piers this approach is further

Table 1

Assumed Mechanical Characteristics of the Stone Masonry

\begin{tabular}{|l|c|c|c|c|c|}
\hline & $\begin{array}{c}\text { Young's } \\
\text { Modulus } \\
\left(\mathrm{N} / \mathrm{mm}^{2}\right)\end{array}$ & $\begin{array}{c}\text { Poisson's } \\
\text { Ratio }\end{array}$ & $\begin{array}{c}\text { Compressive Strength } \\
\left(\mathrm{N} / \mathrm{mm}^{2}\right)\end{array}$ & $\begin{array}{c}\text { Tensile Strength } \\
\text { normal /parallel } \\
\text { bed-joint }\left(\mathrm{N} / \mathrm{mm}^{2}\right)\end{array}$ & $\begin{array}{c}\text { Shear strength } \\
\mathbf{f}_{\text {vko }}\end{array}$ \\
\hline Limit values & 1500 & 0.2 & 3.8 & $0.250 / 0.800$ & 0.19 \\
\hline
\end{tabular}




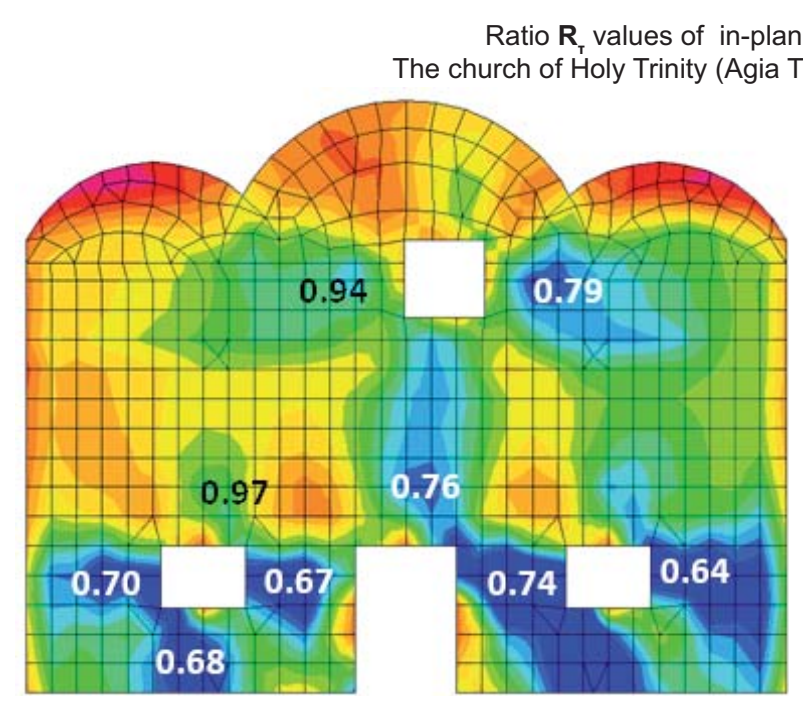

Fig. 6a. Non-Deformable Foundation

Internal Transverse Wall, 0.9G+1.4Ey

detailed here for the in-plane limit-state behaviour of vertical masonry walls and piers. For this purpose, the results of the linear-elastic numerical analysis, in terms of stress resultants $(\boldsymbol{N}, \boldsymbol{M}, \boldsymbol{H}$, figure 7$)$, are then utilized.

\subsection{In-plane bearing capacity against sliding together with the flexural capacity}

For this purpose use could be made of the provisions of Eurocode 6 . For the masonry pier which is studied here the shear strength of the masonry $\left(f_{v k}\right)$ is the minimum value of the following:

$$
\boldsymbol{f}_{v k}=\boldsymbol{f}_{v k 0}+0.4 \boldsymbol{\sigma}_{n}(\text { Eq. } 1 \text { stated before })
$$

where $\sigma_{n}$ is the value of the average normal stress, $\boldsymbol{f}_{v k 0}$ the shear strength of the masonry for zero normal stress that is specified by the provisions of Eurocode 6.

$$
\boldsymbol{f}_{v k}<0.065 \boldsymbol{f}_{b}
$$

where $f_{b}$ is the compressive strength of the masonry unit.

$$
\boldsymbol{f}_{v k}<\boldsymbol{f}_{v k l i m}
$$

where $\boldsymbol{f}_{v k l i m}$ is the upper shear strength of the masonry, as specified by the national appendix of each member state.

The distribution of axial stress $\left(\sigma_{n}\right)$ normal to a bed joint with thickness equal to the pier thickness that develops at this horizontal section is assumed to be one of the four simple cases depicted in figures $8 \mathrm{a}$ to $8 \mathrm{~d}$, which are incorporated in many design provisions. In order to obtain the shear capacity against sliding one should properly choose which of these four cases of normal stress distribution develops based on the geometry, the stress resultants $\left(\boldsymbol{N}_{\boldsymbol{y}^{\prime}} \boldsymbol{Q}_{\boldsymbol{y}^{\prime}} \boldsymbol{M}_{\boldsymbol{y}}\right)$ and the masonry compressive and tensile strength values, $\boldsymbol{f}_{\boldsymbol{k} d}$ and $\boldsymbol{f}_{x k 1 d}$ respectively. These strength values as well as the checks being performed are based on the provisions of Euro-

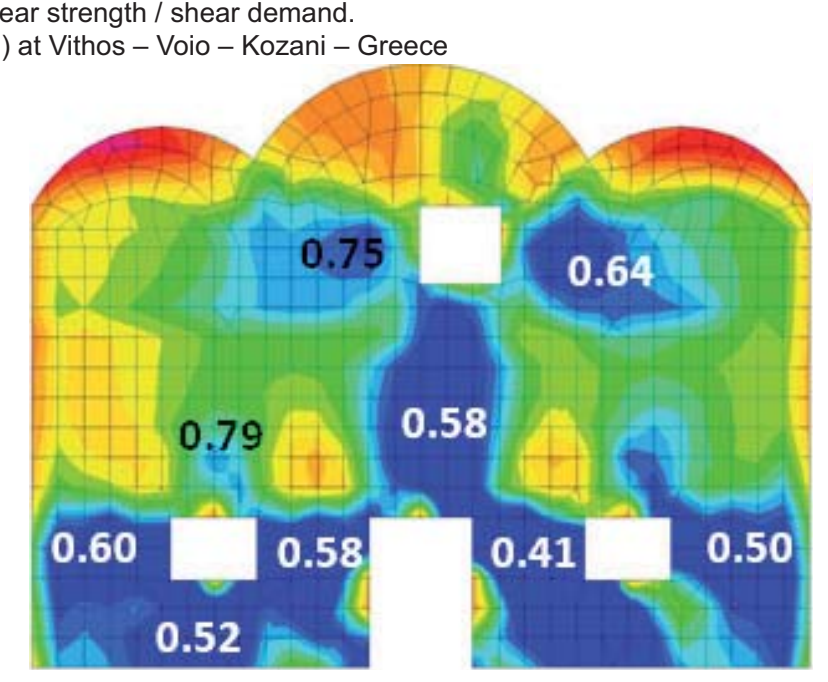

Fig. 6b. Deformable Foundation Internal Transverse Wall, 0.9G+1.4Ey

code 6; however, provisions from other codes can be easily incorporated. Together with the normal stress distribution, the length of the compressive zone $\left(I_{c}\right)$ is also calculated as well as the value of the average normal stress $\left(\sigma_{n}\right)$, which is assumed to act in this compressive zone as depicted in figures $8 \mathrm{a}$ to $8 \mathrm{~d}$. Use is made of both the compressive zone length and the average normal stress value for calculating next the masonry shear capacity against sliding (see equations 1, 3 and 4).

\subsection{In-plane bearing capacity of a masonry pier against diagonal tension}

This is done based on the following formula (Eq. 5) given by Bernardini et al (1980) by Turnsek and Cacovic (1971) and by Tomazevic (2009). It is assumed that the tensile strength of the masonry $\sigma_{t}=f_{x k 1}$ depends on the maximum average shear stress of a horizontal section of the masonry pier and on the average compressive stress $\sigma_{d}=\boldsymbol{N} / \boldsymbol{A}$ that develops at the same location where $\boldsymbol{A}$ is the area of this section and $\boldsymbol{N}$ the compressive load.

$$
\sigma_{f}=f_{x k 1}=\sqrt{\left(\sigma_{d} / 2\right)^{2}+\left(b \tau_{\max }\right)^{2}}-\sigma_{d} / 2 \quad \text { (Eq. 5) }
$$

Where $\boldsymbol{b}$ represents the shear stress distribution factor, which is related to the stress distribution on the section and the slenderness ratio of the wall. It can be assumed that $\boldsymbol{b}=\boldsymbol{h} / \boldsymbol{I}$, where $\boldsymbol{h}$ is the height and $\boldsymbol{l}$ is the length of the pier. In this case $\boldsymbol{b}=1.5$ is the upper limit value and $\boldsymbol{b}=1$ is the lower limit value. From the above relationship the value of can be obtained based on the values of $\sigma_{t}=f_{x k 1}$ and $\sigma_{d}$ :

$$
\tau_{\max }=\frac{f_{x k 1}}{b} \sqrt{f_{x k 1}+\sigma_{d}}
$$

The formulas and procedures described in 4.1. and 4.2 are incorporated in an expert system that can predict the bearing capacity of a given pier and the expected mode of failure of a given stone masonry pier (Manos et al., 2015(1)). The validity of this expert 


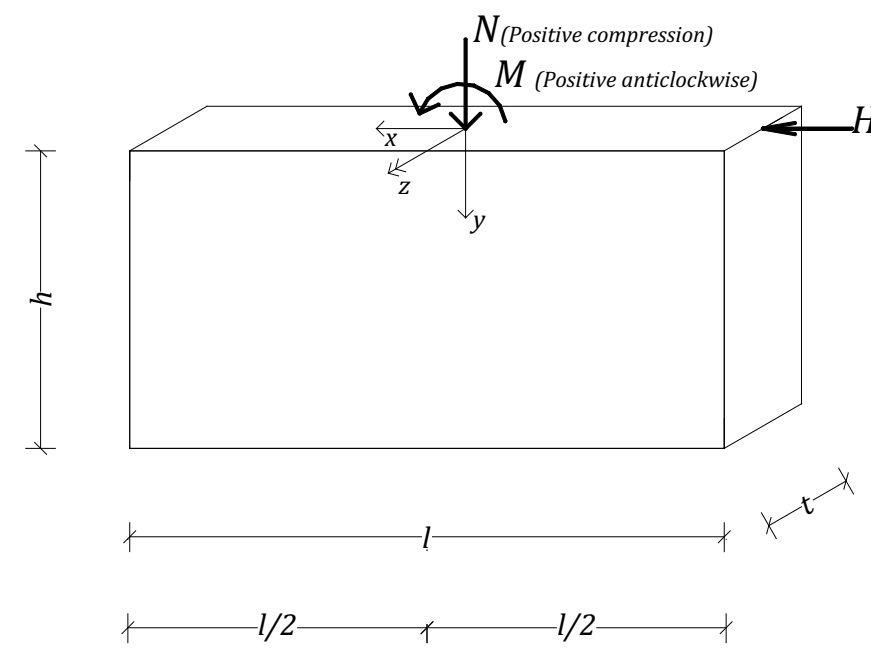

Based on these values, limit-state patterns of axial stress $\left(\sigma_{n}\right)$, normal to a bed joint for a given horizontal crosssection are found, as depicted in figures 8 a to $8 d$, which are realistic for stone masonry elements. The objective here is to predict whether the transfer of these stress resultants can be done successfully or not, depending on the shear and flexural capacity of this structural element, as defined at a cross section located at a distance equal to $\boldsymbol{y}$ from the upper boundary $\boldsymbol{N}_{\boldsymbol{y}}, \boldsymbol{Q}_{\boldsymbol{y}}, \boldsymbol{M}_{\boldsymbol{y}}$. This is briefly outlined in 4.1 and 4.2. for the in-plane behaviour.

Fig. 7. Single stone-masonry pier being stressed at its upper boundary

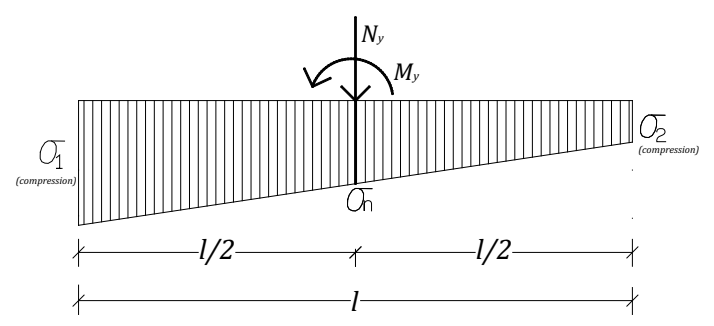

a. Case 1: Axial stress distribution is compressive along all the length of the examined mortar bed joint of the pier:

$\sigma_{1} \geq 0$ and $\sigma_{2} \geq 0$

$\sigma_{1}<$ than the masonry compressive strength $\boldsymbol{f}_{k d}$

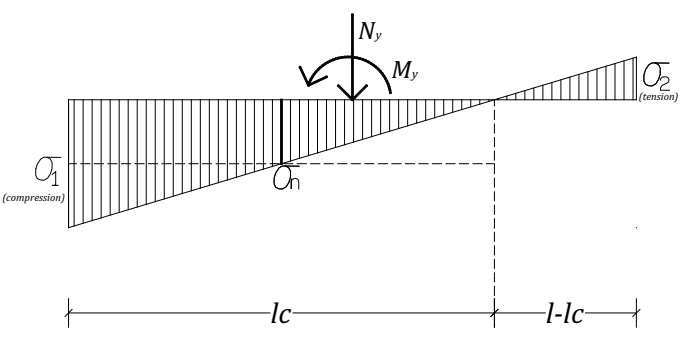

b. Case 2: $\quad \sigma_{2}<$ than the tensile limit stress $f_{x k 1 d}$; consequently, the tensile zone is assumed to be active:

$\sigma_{1}>0 ; \sigma_{2}<0 ;\left|\sigma_{1}\right| \leq f_{x k 1 d}$

and $\sigma_{1}<\mathrm{f}_{k d}$

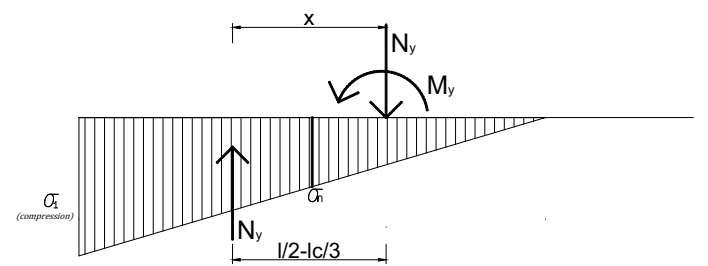

c. Case 3 : There is tension at the right fiber of the cross section, larger than the tensile limit stress $f_{x k 1 d}$; consequently, the tensile zone is assumed to be inactive:

$\sigma_{1}>0 ; \sigma_{2}<0 ;\left|\sigma_{2}\right|>f_{x k 1 d}$

and $\sigma_{1}<f_{k d}$

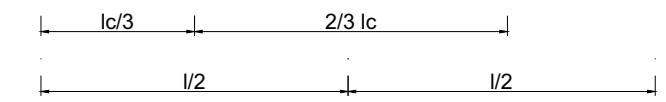

d. Case 4: The tensile zone remains inactive but the compressive zone becomes narrower than before.

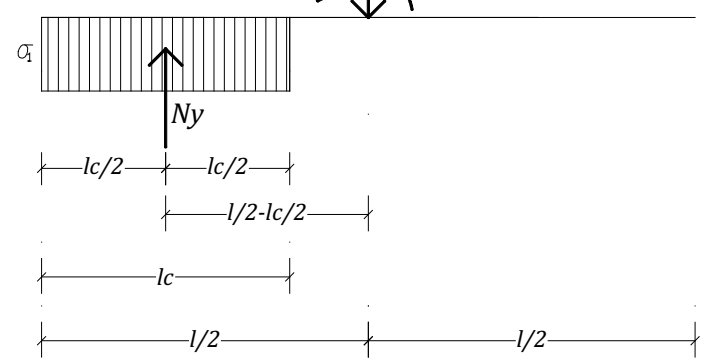

$\sigma_{1}>0 ; \sigma_{2}<0 ;\left|\sigma_{2}\right|>f_{x k 1 d}$ and $e=\frac{M_{y}}{N_{y} l} \geq 0,45$

(Towards flexural failure):

Fig. 8. Normal to the bed-joint axial stress distribution patterns 
system was confirmed by comparing its predictions with the observed laboratory performance, in terms of capacity and mode of failure, of a considerable number of masonry piers. A new series of such comparisons are currently under way, as briefly described in section 5 .

\section{Expected seismic performance on the basis of non-linear numerical simulations}

As already mentioned, non-linear inelastic "push-over" types of numerical analyses were also performed whereby stone masonry structures and specimens are subjected first to the permanent vertical loads and then the seismic horizontal forces (Manos et al., 2008, 2015(1,2)), Vintzileou, 2008). In what follows, the numerical non-linear step-by-step approach will be applied to simple stone masonry specimens that have been subjected in the laboratory to certain load combinations that resulted in a state of in-plane stress distribution resembling the state of stress of vertical stone masonry piers subjected to stress resultants from the combined gravitational and seismic forces.

\subsection{Numerical simulation of the behaviour of a "short" pier stone masonry specimen}

A number of "short" stone masonry specimens with dimensions $500 \mathrm{~mm}$ by $500 \mathrm{~mm}$ in plan and $300 \mathrm{~m}$ in height, were built at the laboratory of Strength of Materials and Structures of Aristotle University using lime mortar and natural stones (Manos et al., 2015(2,3)). The lime mortar had such a composition as to be representative of old relatively weak mortars commonly used in the past. A series of such samples were tested accompanied by constant vertical compression with variable horizontal shear load at the top having fixed the base of each specimen against sliding, as shown in figure 9. This set-up was designed in an effort to obtain an estimate of the shear strength at a limit state which represents the failure of the mortar bed-joint as depicted in figure 10.

Based on these experimental results, the MohrCoulomb limit state criterion (equation 1) can be approximately quantified. The numerical model of this tested specimen is depicted in figure 11 , being supported and loaded in the same way as the "short" pier specimen during testing. The non-linear behavior was simulated utilizing the capabilities of the commercial software ABAQUS (Hibbit et al., 2010).

The obtained numerical against the measured behaviour of this specimen, in terms of shear stress $(\boldsymbol{T})$ versus shear strain $(\boldsymbol{V})$, is plotted in figure 12. As can be seen, the agreement between the non-linear numerical predictions and the observed behaviour, in terms of $\boldsymbol{T} \boldsymbol{T} \boldsymbol{\gamma}$ plots, is reasonably good (Manos et al., 2015(1)). The numerical predictions of the distribution of the plastic strains as well as the tensile principal stresses are plotted in figures 13a and
$13 \mathrm{~b}$, respectively. When comparing the distribution patterns depicted in figures $13 \mathrm{a}$ and $13 \mathrm{~b}$ with the observed failure mode during testing, depicted in figure 10 , reasonably good agreement can again be seen.

5.2. Numerical simulation of a "square" stone masonry pier specimen with simultaneous com. pression and horizontal load

A stone masonry almost "square" pier is examined next having a length equal to $I=1500 \mathrm{~mm}$, a height equal to $\boldsymbol{h}=1400 \mathrm{~mm}$ and a thickness equal to $t=500 \mathrm{~mm}$, thus a length over height ratio $(I / h)$ equal to.1.071 (quite close to 1.0). This square pier specimen was built at the laboratory of Strength of Materials and Structures of Aristotle University with the same stones and mortar that were used to construct the short pier specimen presented before. A number of square and short pier specimens using mortars of different compositions were also constructed and tested; however, space limitations prohibit the presentation of their performance. The square pier specimens were subjected to a uniform compression equal to approximately $0.12 \mathrm{Mpa}$ at their upper boundary. The horizontal load, as shown in figures $14 \mathrm{a}$ and $14 \mathrm{~b}$, results from the imposed horizontal displacement at the upper boundary which reaches a value equal to $10 \mathrm{~mm}$ at the final stages.

Figure 14a depicts the experimental set up showing the resulting horizontal load at the top of the stone masonry pier whereas figure $14 \mathrm{~b}$ is the corresponding numerical simulation. The vertical load is also shown as applied at two locations at the top of a steel beam resting on top of the specimen. This steel beam is capable of sliding horizontally through a sliding interface between this steel beam and the stone masonry specimen. The sliding surfaces have a coefficient of friction less than $2 \%$, thus providing very little horizontal resistance during the application of the horizontal load to the specimen. Moreover, a system of load cells and low-stiffness springs is provided at each location of vertical load application. Using these low-stiffness springs the variation of the vertical load that results from the vertical deformations of the specimen during the combined horizontal and vertical load sequence is minimized. In any case, the amplitude of the vertical load and its variation in each one of these two locations is recorded continuously by the two load cells. The locations where these vertical loads are applied together with the locations of the sliders (whereby these vertical loads are transferred to the specimen) are chosen in such a way as to have an almost uniform distribution of axial stresses normal to the bed-joints of the stone masonry specimen. The vertical loads, which were applied at this stone masonry pier at the initiation of testing, were equal to $49 \mathrm{KN}$ at each vertical loading location. The special gravity of the masonry is considered equal 


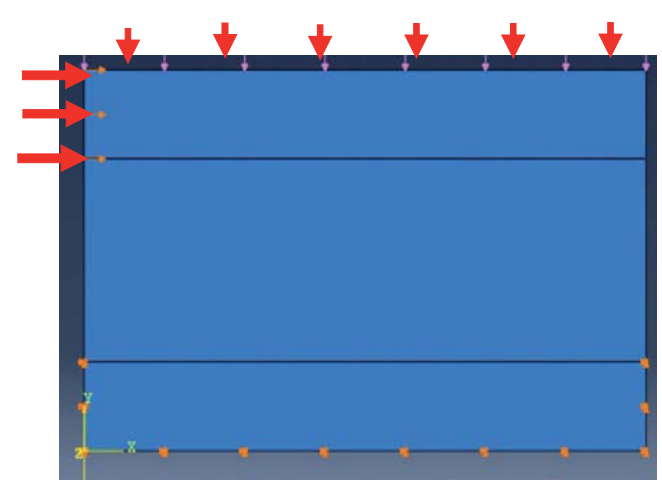

Fig. 9. Compression and shear loading applied at the short stone masonry piers utilizing hydraulic actuators

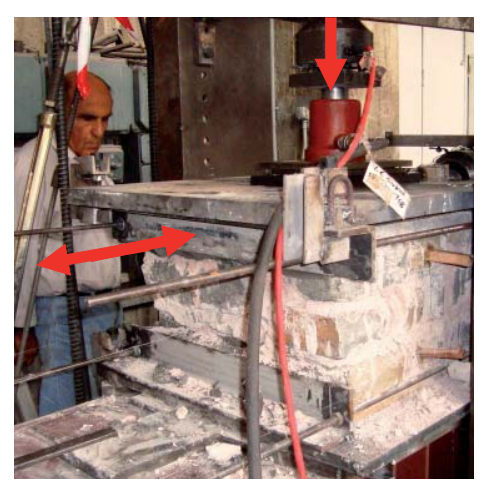

\author{
Fig
}

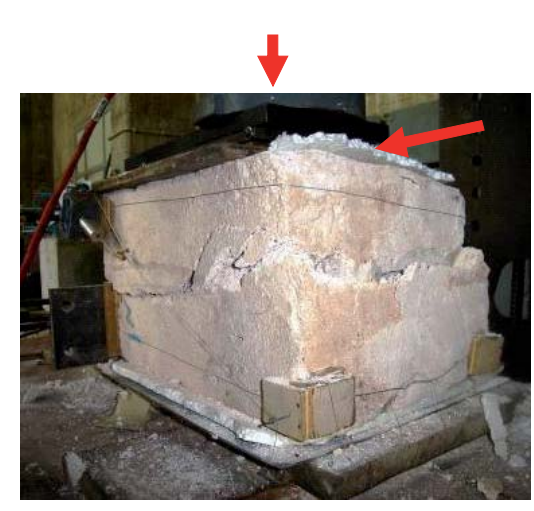

Fig. 10. Observed damage patterns of the short pier

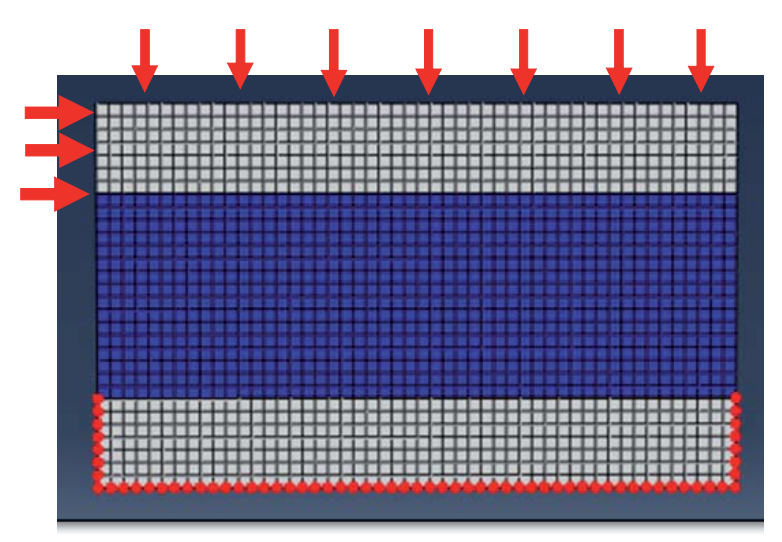

Fig. 11. Numerical simulation of the short pier tested specimen

to $22.0 \mathrm{KN} / \mathrm{m} 3$. This "square" pier is assumed to be constructed by relatively weak masonry; therefore, the Young's modulus for the horizontal load is presumed to be equal to $200 \mathrm{MPa}$. Both the average normal and shear stress at a horizontal cross-section of the specimen, corresponding to an ideal bed-joint was obtained by dividing the measured applied total horizontal and vertical load by the net cross-section (approximately $75 \%$ of the gross cross-section due to the building detail). Figures $15 \mathrm{a}$ and $15 \mathrm{~b}$ depict the variation of the shear stress versus the shear strain (blue line). The horizontal load was applied in a cyclic low-frequency seismic-type manner.

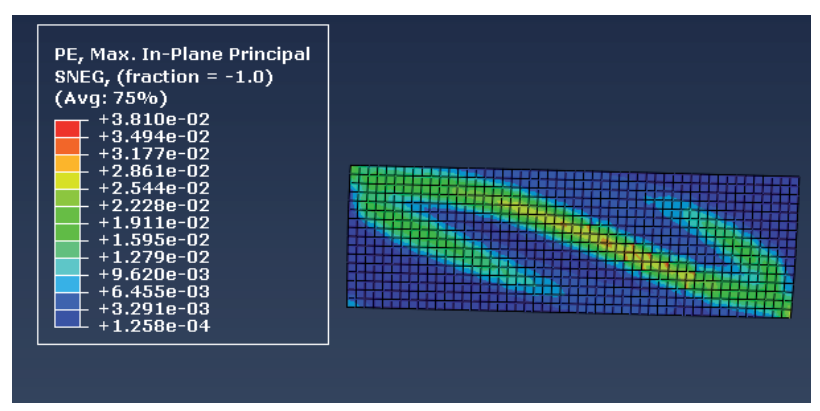

Fig. 13a. Distribution of predicted plastic strains for the short pier

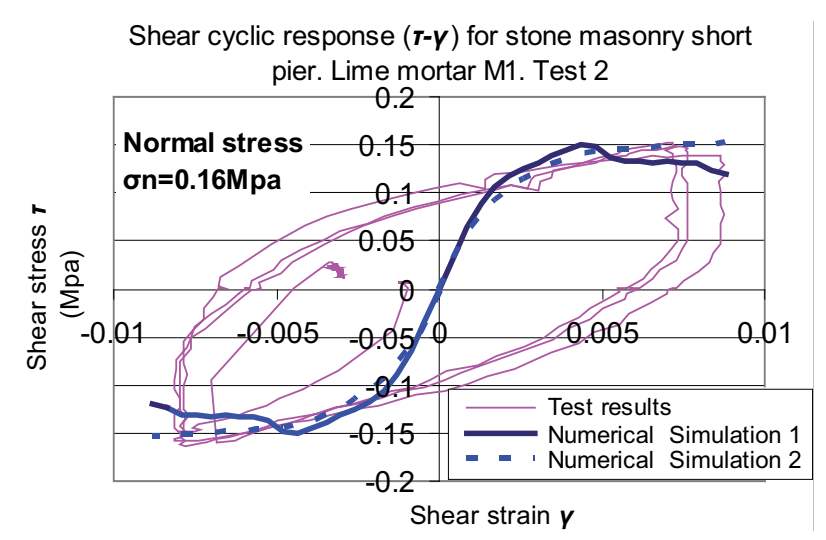

Fig. 12. Short pier observed and numerically predicted shear stress versus shear strain

In figures $15 \mathrm{a}$ and $15 \mathrm{~b}$ the variation of the compressive axial stress normal to the bed-joint is also plotted (pink line using the far right axis with the negative values). As can be seen in figure 15a, the maximum shear stress was equal to $0.09 \mathrm{MPa}$ for Test 6 . For this test the corresponding average axial stress value was equal to $-0.16 \mathrm{MPa}$ exhibiting a relatively small variation around this value during cyclic loading. On the contrary, the variation of the axial stress during cyclic test 7 reached a value equal to $-0.26 \mathrm{MPa}$ that corresponded to a shear stress value equal to $0.15 \mathrm{MPa}$. At the reverse cycle, the axial stress value was equal to $-0.12 \mathrm{MPa}$ when

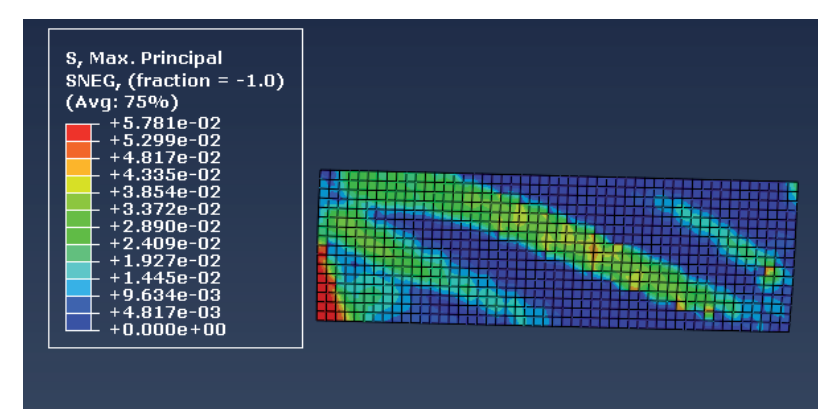

Fig. 13b. Distribution of predicted tensile principal stresses for the short pier. 
the corresponding shear stress value was equal to $0.09 \mathrm{MPa}$, as was the case for test 6 .

The measured variation of horizontal load $(H)$ versus horizontal displacement $(\delta)$ at the top of the specimen for tests 6 and 7 is depicted in figure 16 . In the same figure the numerical predictions are also plotted as resulting from the non-linear numerical simulation. As can be seen, the comparison between predicted and observed $\mathrm{H}-\delta$ response is reasonably good for Test 6 . For test 7 there is a distinct difference between observed and predicted response when the horizontal load attains negative values. This is attributed to the variation of the vertical load at this stage of the experiment that reached much higher absolute values, as already mentioned before on the basis of figure $15 \mathrm{~b}$. This was not accounted for up to now in the numerical simulation that kept constant throughout the vertical load, as already described and equal to $49 \mathrm{KN}$ at each location. Additional numerical simulations are required to account for

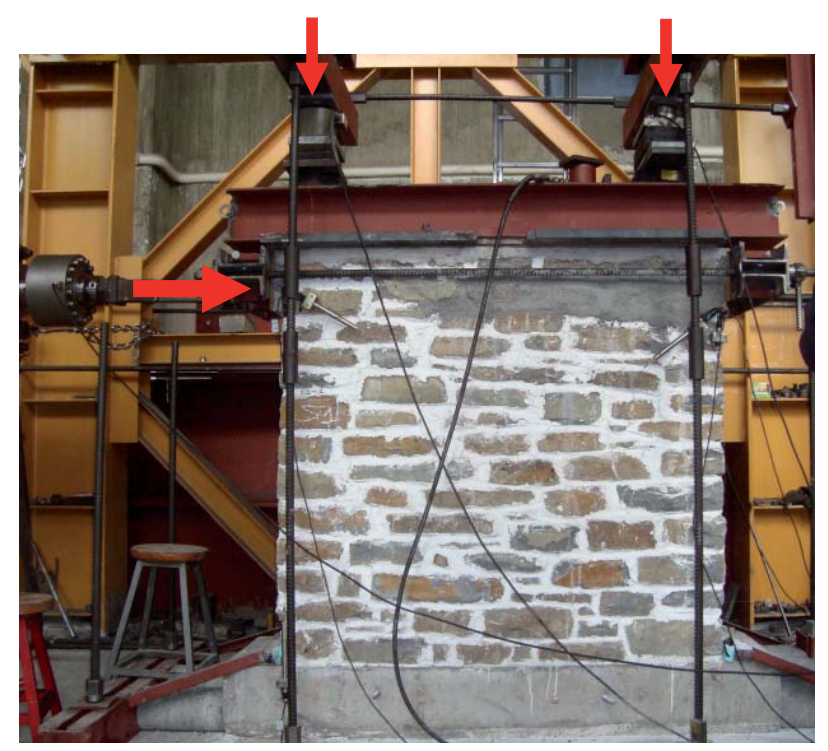

Fig. 14a. Stone masonry wall specimen S1M1. Loading arrangement being utilized

Stone masonry wall S1M1

Vertical preloading $49 \mathrm{KN}+49 \mathrm{KN}$ Test 6

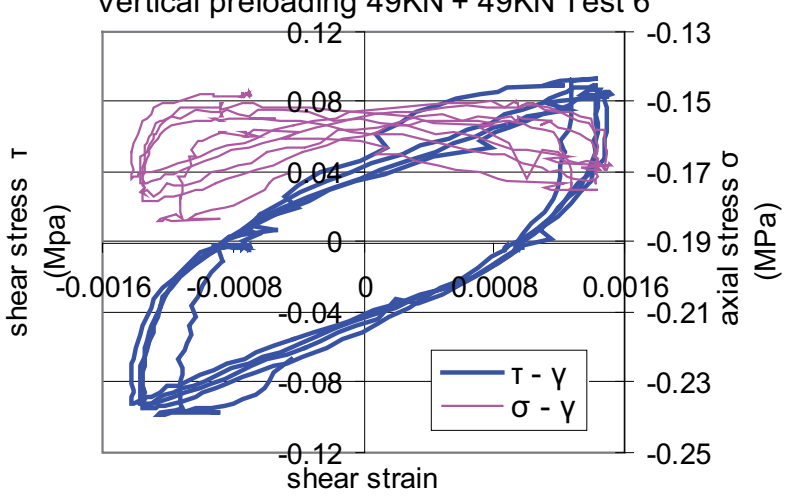

Fig. 15a. Variation of the measured shear / axial stress versus the shear strain. Test 6 the observed vertical load variation. The numerically predicted horizontal deformation pattern resulting from the non-linear simulation is depicted in figure 17; this deformation pattern is for the maximum horizontal load equal to $57.71 \mathrm{KN}$, which was reached for horizontal displacement at the top of the pier equal to $\delta=1.85 \mathrm{~mm}$.

Figure 18 depicts the damage patterns in the form of wide diagonal cracks that were formed in this stone masonry wall specimen (S1M1) and were photographed after the end of Test 7 . Figure 19 depicts the distribution of the plastic strains that developed in the non-linear numerical simulation when the horizontal load dropped for the first time from its maximum value to $49.96 \mathrm{KN}$ and horizontal displacement at the top of the pier reached a value equal to $\delta=2.4 \mathrm{~mm}$. As can be seen, the formation of the observed diagonal crack pattern is to a certain extend predicted by the non-linear numerical simulation. Next, the expert system, which was briefly

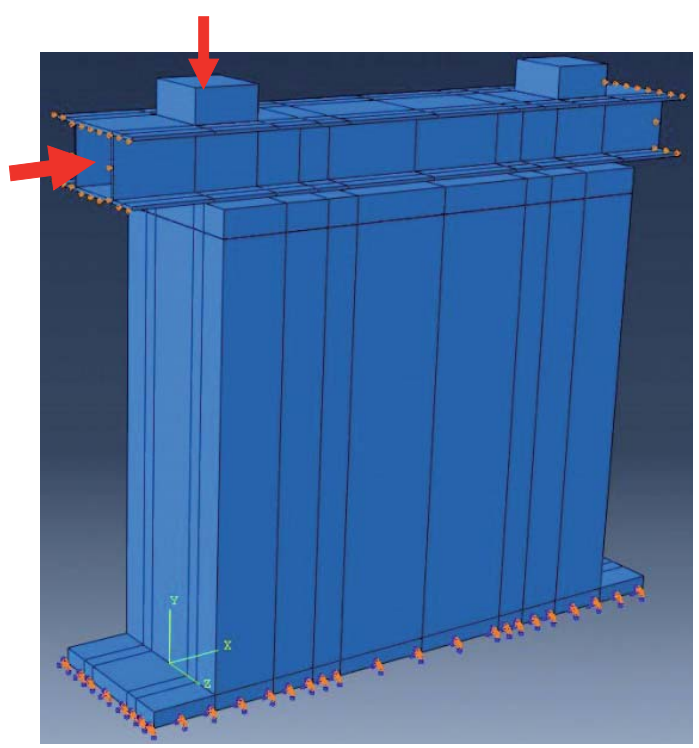

Fig. 14b. Numerical simulation of the loading arrangement for wall specimen S1M1

Stone masonry wall S1M1

Vertical preloading $49 \mathrm{KN}+49 \mathrm{KN}$ Test 7

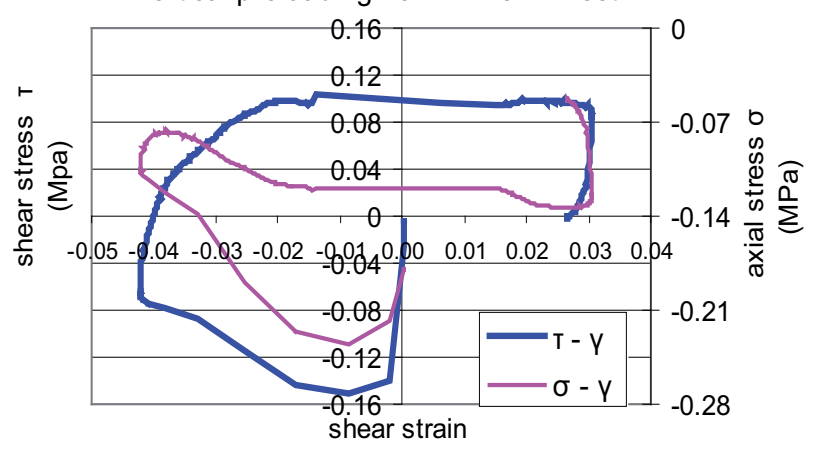

Fig. 15a. Variation of the measured shear / axial stress versus the shear strain. Test 7 


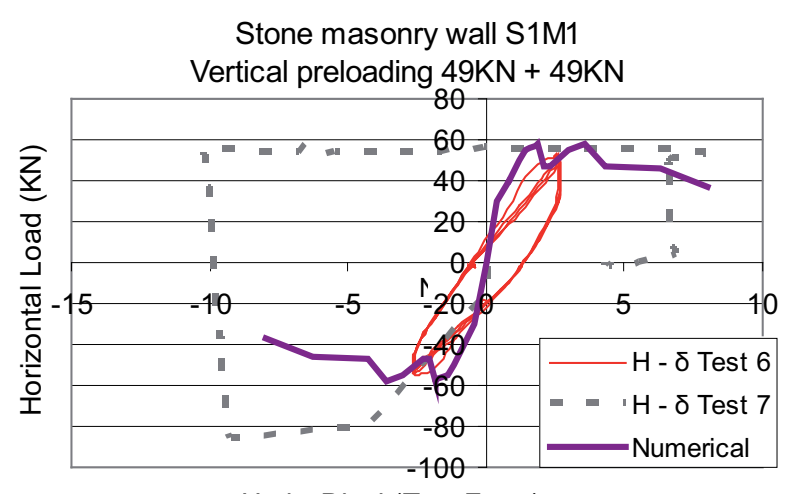

Horiz. Displ (Top-Foun) mm

Fig. 16. Variation of the horizontal load versus the horizontal displacement at the top. Tests 6,7 together with numerical predictions

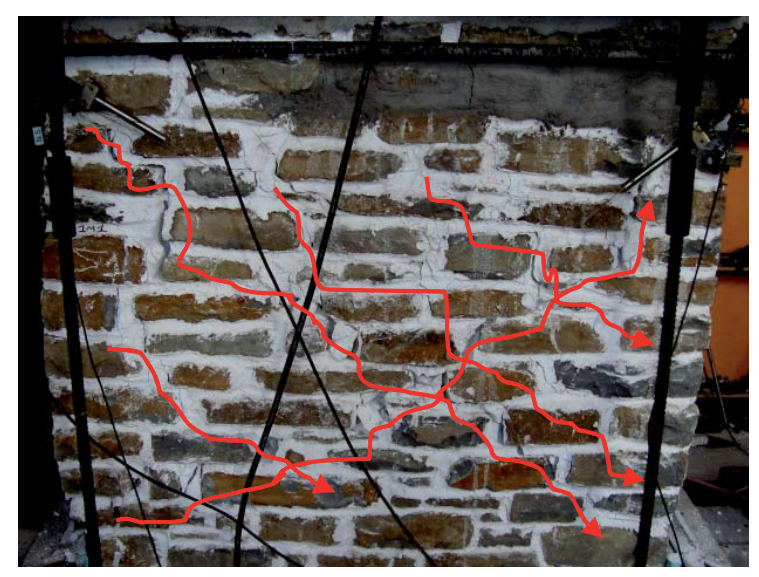

Fig. 18. Diagonal cracks that developed in the stone masonry specimen S1M1

described in section 4.2, was employed for this tested stone masonry specimen (S1M1) with the following particular geometric and mechanical characteristics that are relevant to this specimen: Length $=1.5 \mathrm{~m}$, Height $=1.2 \mathrm{~m}$, Thickness $=0.4 \mathrm{~m}$ (to account for $25 \%$ reduction), Compressive strength $\mathbf{f}_{\mathrm{k}}=4.35 \mathrm{MPa}$, Initial shear strength $\mathbf{f}_{\mathrm{vko}}=0.06 \mathrm{MPa}$, Tensile strength normal to the bed-joint $\mathbf{f}_{\mathrm{xk} 1}=0.05 \mathrm{MPa}$, Initial compressive force $\boldsymbol{N}=98 \mathrm{KN}$, Initial bending moment $\boldsymbol{M}=0$. The subsequent performance check was for a crosssection at a distance of $y=0.7 \mathrm{~m}$ from the top (see section 4 and figures 7,8 ) the maximum horizontal load capacity, predicted by this expert system, is $\boldsymbol{H}=64.45 \mathrm{KN}$ and the predicted mode of failure is diagonal tension (section 4.2). Both predictions by the expert system agree reasonably well with the observed performance (figures 16 and 18).

\section{Conclusions}

1. The seismic behaviour of stone masonry Greek Orthodox churches is examined in this paper. This study was based on long term observations of the seismic performance of this type of structures that developed structural damage when subjected to actual moderate to strong earthquake ground motions during the last 50 years.

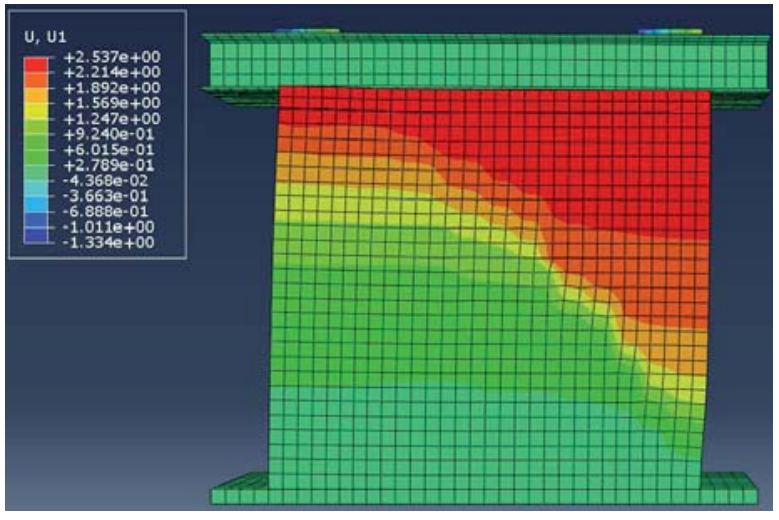

Fig. 17. Numerically predicted horizontal deformations for the stone masonry specimen. Maximum value at top $1.85 \mathrm{~mm}$

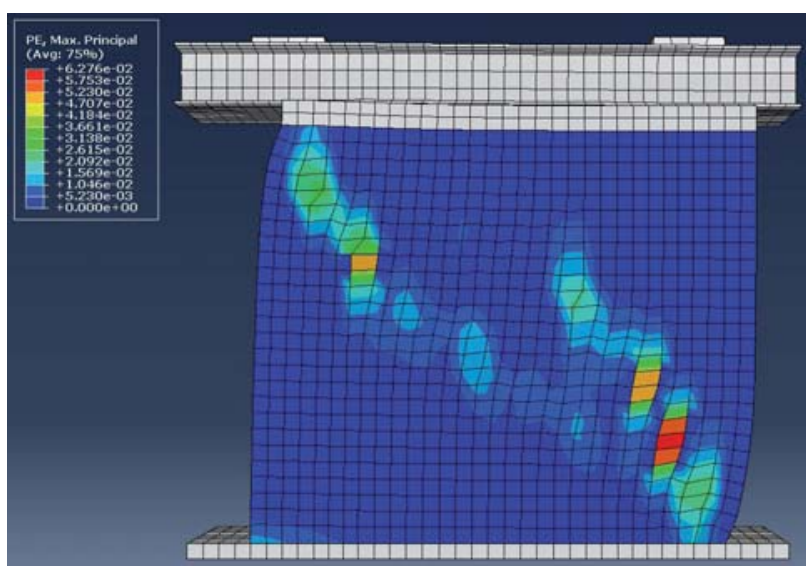

Fig. 19. Distribution of numerically predicted plastic strains for $\mathrm{H}=43,41 \mathrm{KNt} \mathrm{Ux}=6,58 \mathrm{~mm}$

2. A methodology is first described that was based on a linear numerical simulation and a dynamic spectral method of analysis to obtain the demands. The corresponding capacities were next obtained by considering in-plane and out-of-plane limitstates that are well established from experimental investigations and are included in current design procedures for contemporary masonry structures. The difficulty here was to reach with a good degree of approximation the relevant mechanical old stonemasonry strength values that are required in order to calculate these capacities. In-situ and laboratory tests can be mobilised for this purpose. Moreover, the significance of the soil-foundation deformability was discussed.

3. Good agreement was achieved when comparing the predicted with the observed performance by applying this linear limit-state methodology in a number of stone masonry Greek Orthodox churches whose seismic behaviour has been well documented in the past.

4. An expert system was developed that can be used to facilitate the results of the above methodology for vertical stone masonry structural elements. The basis of this expert system for 
calculating the capacities for in-plane demands was briefly described.

5. Next, certain type of non-linear numerical simulation was examined towards reaching realistic predictions of the observed performance of stone masonry structural elements. For this purpose use was made of experimental set-ups employing relatively simple stone masonry specimens of prototype dimensions which were constructed with materials resembling old stone masonry. These specimens were subjected to in-plane combined compression, shear and flexure in such a way as to develop stress fields that are similar to the state of stress prototype stone masonry structural elements develop during combined gravitational forces and seismic actions. The obtained measured behaviour from these tests was then utilized to validate the employed non-linear numerical simulations. As was demonstrated from these comparisons a realistic estimate was obtained of the observed seismic type behaviour by these non-linear numerical simulations. Following further validation these nonlinear simulations will next be employed in more complex structural components.

6 . The obtained results from these specimens were utilized to also validate the expert system based on this limit-state methodology. Again, the observed behaviour was predicted with reasonable accuracy in terms of bearing capacity and mode of failure by this expert system.

\section{Acknowledgements}

The assistance of Dr. V. Kourtidis and Th. Koukouftopoulos for performing the experiments is gratefully acknowledged. Dr. V. Soulis, L. Kotoulas, O. Felekidou, V. Matsou, E. Kozikopoulos, A. Diagouma, Dr. K. Katakalos, Dr. M. Demosthenous, Dr. J. Thauampteh, V. Karamitsios, A. Koutsianou, P. Lipiridou, L. Pappas, K. Sarigianni, G. Koidis, E. Papanaoum, S. Vacaro and N. Parcharidis are also thanked.

\section{References}

Bernardini A, Modena C, Turnsek V, Vescovi U (1980) A comparison of three laboratory test methods used to determine the shear resistance of masonry walls" Proc. 7th WCEE, vol 7, IAEE, Istanbul, pp 181-184.

Betti, M. \& Vignoli, A. "Assessment of seismic resistance of a basilica-type church under earthquake loading: Modelling and analysis", Advances in Engin. Software 39 (2008) 258-283

Eurocode 6 part 1: Design of structures for earthquake resistance - Part 1: General rules, seismic actions and rules for buildings, FINAL DRAFT prEN 1998-1, December 2003.

Eurocode 8: Design of structures for earthquake resistance - Part 1: General rules, seismic actions and rules for buildings, FINAL DRAFT prEN 1998-1, December 2003.

GEER - EERI - ATC - Cephalonia GREECE Earthquake Reconnaissance January 26th/ February 2nd 2014 Version 1: June 62014

Gulkan P., Clough R.W., Manos G.C. and Mayes R.L., (1990), "Seismic Testing of Single-story Masonry Houses : Parts 1\&2", Journal of Str. Eng. ASCE, Vol. 116, No 1, Jan. 1990, pp. 235-274.

Hibbitt, Karlsson, Sorensen. Inc. ABAQUS user's manual volumes I-V and ABAQUS CAE manual. Version 6.10.1. Pawtucket, USA; 2010.

Manos, G.C.( 1994) Seismic Code of Greece, Chapter 17, International Handbook of Earthquake Engineering: "Codes, Programs and Examples", edited by Mario Paz, by Chapman and Hall, ISBN 0-412-98211-0.

Manos G.C., Soulis V., Diagouma A. (2008) "Numerical Investigation of the behaviour of the church of Agia Triada, Drakotrypa, Greece", Journal in Advances in Engin. Software 39, 284-300.

Manos, G. C. Soulis, V. J. Felekidou, O. Koutsianou, A. Lipiridou, P. "The dynamic and earthquake response of Greek Byzantine and Post-Byzantine Basilicas", COMDYN 2009, Greece.

Manos G., Soulis V., Felekidou O., Matsou V. (2010(1)) "A Numerical Investigation of the Dynamic and Earthquake Behaviour of Byzantine and Post-Byzantine Basilicas", 9th U.S. and 10th Canadian Earthq. Eng. Conf., Canada.

Manos G,, Soulis V., Felekidou O. (2010(2)) "Numerical Study of the Dynamic and Earthquake Behavior of Byzantine and Post-Byzantine Basilicas", 8th International Masonry Conference, 2010, Dresden, Germany.

Manos G.C., (2011) "Consequences on the urban environment in Greece related to the recent intense earthquake activity", Int. Journal of Civil Engineering and Architecture, Volume 5, No. 12 (Serial No. 49), pp. 1065-1090.

Manos, G.C, Kotoulas, L., Matsou, V., Felekidou, O. (2013(1)) "Dynamic behaviour of Greek Post-Byzantine churches with foundation deformability and evaluation of their earthquake performance", CompDyn2013, 12-14 June 2013, Greece. 
Manos G.C., Soulis V., Karamitsios N. (2012) "The Performance of Post-Byzantine churches during the Kozani-1995 Earthquake - Numerical Investigation of their Dynamic and Earthquake Behavior”, 15WCEE, Portugal.

Manos G. C. \& Karamitsios N. (2013(2)) "Numerical simulation of the dynamic and earthquake behavior of Greek postByzantine churches with and without base isolation", Earthquake Engineering Retrofitting of Heritage Structures, Design and evaluation of strengthening techniques, pp. 171-186, Edited By: S. Syngellakis, Wessex Institute of Technology, UK, ISBN: 978-1-84564-754-4, eISBN: 978-1-84564-755-1.

Manos, G.C. \& Kotoulas, L. (2014) "Earthquake Performance of Greek Post-Byzantine Churches with Foundation Deformability “ Proc. 2nd Int. Conf. on Protection of Historical Constructions, pp. 297-303, ISBN 978-975-518-361-9.

Manos, G.C., Kotoulas, L., Felekidou, O., Vaccaro, S. and Kozikopoulos, E. (2015(1)) "Earthquake damage to Christian Basilica Churches - Application of an expert system for the preliminary in-plane design of stone masonry piers", Int. Conf. STREMAH 2015.

Manos G.C. \& Kozikopoulos E. , (2015(2)) "The dynamic and earthquake response of Basilica Churches in KefaloniaGreece including soil-foundation deformability and wall detachment”, CompDyn2015, Krete-Greece, 2015.

Manos, G.C. Kotoulas, L., Matsou V. and Felekidou, O. "Dynamic and Earthquake Behaviour of Greek Post-Byzantine Churches with Foundation Deformability-Experimental. Investigation of Stone Masonry Material Properties", Springer International Publishing Switzerland 2015(3), I.N. Psycharis et al. (eds.), Seismic Assessment, Behavior and Retrofitof Heritage Buildings and Monuments, Computational Methods, in Applied Sciences 37, DOI10.1007/978-3-319-16130-3_9 Papazachos, B. and Papazachou, K., 1989, 1997, 2003. The earthquakes of Greece, Zitis Publ., Thessaloniki, 356 pp., 304 pp., 286 pp. (in Greek).

Provisions of Greek Seismic Code 2000, EPPO, Earthquake Planning and Protection Organization Athens, Greece, December 1999.

Provisions of Greek Seismic Code with revisions of seismic zonation, Government Gazette, $\Delta 17 \alpha / 115 / 9 / \Phi N 275$, No. 1154, Athens, 12 Aug. 2003.

Ramalho, Marcio Antonio et al. (2008) "A numerical model for the description of the nonlinear behaviour of multi-leaf masonry walls", Advances in Engineering Software 39 (2008) 249-257.

Tomaževič M. (2009) "Shear resistance of masonry walls and Eurocode 6: shear versus tensile strength of masonry“, Materials and Structures, August 2009, Volume 42, Issue 7, pp 889-907.

Turnsek V, Cacovic F (1971) Some experimental results on the strength of brick masonry walls. In: Proceedings of the 2nd international brick-masonry conference. British Ceramic Society, Stoke-on-Trent, pp 149-156

Vintzileou, E. (2008) "Effect of Timber Ties on the Behavior of Historic Masonry", American Society of Civil Engineers, Journal of Structural Engineering, Vol. 134, No. 6, June 1, 2008. CASCE, DOI: 10.1061/ (ASCE) 0733-9445 (2008) 134:6(961). 